\title{
Separating Reputation, Social Influence, and Identification Effects in a Dictator Game
}

\author{
Maroš Servátka和
}

March 2007

\begin{abstract}
This study explores the ways in which information about others' actions affects one's own behavior in a dictator game. The experimental design discriminates behaviorally between three possible effects of recipient's within-game reputation on the dictator's decision: reputation causing indirect reciprocity, social influence, and identification. The separation of motives helps to identify the mechanisms of social transmission of impulses towards selfish or generous behavior. The statistical analysis of experimental data reveals that the reputation effects have a stronger impact on dictators' actions than the social influence and identification. I conjecture that an active participation in social norm creation and their enforcement governs subjects' behavior to a higher degree than conformism.
\end{abstract}

Classification codes: C70; C91; D63; D64

Keywords: Experimental economics; Dictator game; Indirect reciprocity; Reputation; Social influence

*Address: Department of Economics, University of Canterbury, Private Bag 4800, Christchurch, 8015, New Zealand; phone: +64-3-3642825; fax: +64-3-3642635; e-mail: maros.servatka@canterbury.ac.nz.

†The author received his Ph.D. from the University of Arizona in May 2006. This paper is based on a dissertation chapter titled "Reputation vs. Social Influence: Which Is Stronger?"

${ }^{\ddagger}$ Acknowledgements: I thank Jim Cox, Martin Dufwenberg, Price Fishback, Tibor Neugebauer, Ron Oaxaca, and participants at ESA and SEA meetings for valuable insights and suggestions. The research funding was provided by the University of Arizona Economic Science Laboratory. 


\section{Introduction}

Social norms together with other-regarding preferences may govern subjects' decisions when making dictator allocations. This paper examines which incentives connected with the existence of social norms cause deviations from standard economic model predictions. More specifically, the experimental design separates three channels through which information about another person affects dictator's choices: reputation, social influence, and identifiability of the recipient. Consider the following situation as an example: Person $\mathrm{Y}$ observes a generous action of person $\mathrm{X}$ towards person Z. Now suppose that person $\mathrm{Y}$ has an opportunity to extend the same courtesy to person $\mathrm{X}$. If $\mathrm{Y}$ indeed decides to treat $\mathrm{X}$ generously, Y's decision could be motivated by indirect reciprocity to reward generous actions or by social influence to behave in a way $\mathrm{X}$ did, thus conforming with social norms for giving. ${ }^{1}$ Also, $\mathrm{Y}$ might choose to be generous due to the mere fact that she is dealing with $\mathrm{X}$ and not some random stranger since the identification of a person can result in different behavior towards them. Lastly, Y might have unconditional preferences for altruism. For ease of exposition throughout the paper I will be referring to reputation, social influence, and identification effects. During the decision-making process these three channels introduce the considerations of indirect reciprocity, adherence to social norms, and cognitive attention given to a particular individual. The goal of the study is to increase our understanding of the ways in which information about others' actions affects one's own behavior in fairness games, and thus help to identify the mechanisms of social transmission of impulses towards selfish or generous behavior.

This paper builds on earlier work of three types: (a) research by Berg, Dickhaut, and McCabe (1995), Knez and Camerer (1995), and Cason and Mui (1998), and others that studies the effects of social history on behavior in fairness games; (b) research by Small and Loewenstein (2003) and others on identifiability, and (c) research by Servátka (2006) on the influence of within-experiment reputation on paired subjects' generosity in dictator games. Berg, Dickhaut, and McCabe (1995) investigate the social history in an investment game where they focus on internalization of social norms. The information about the use of trust within a group of subjects is used as a trust-encouraging factor. The social history treatment identifies conditions

\footnotetext{
${ }^{1}$ Indirect reciprocity was first defined by Alexander (1987). As he states, indirect reciprocity occurs whenever rewards or punishments come from individuals or groups other than those directly involved in a social interaction involving investment or exploitation.
} 
that strengthen the relationship between trust and reciprocity through the social influence argument. Knez and Camerer (1995) use a between-respondent comparison treatment in a three-player ultimatum game to explore the effect of outside options and social comparison. Their results show that the offers were affected by how much the other subjects in the experiment offered. Social influence has been studied experimentally by Cason and Mui (1998). They note that a subject's belief about what corresponds to socially appropriate behavior is based mostly on personal characteristics. However,

"For those subjects who care both about their monetary earnings as well as what constitutes socially appropriate behavior, socially relevant information may affect their beliefs and change their behavior. In particular, if subjects believe that the choice made by another subject gives them useful information, then the availability of information regarding choice made by another subject may change their beliefs regarding what constitutes socially appropriate behavior. This can in turn change their choices." (p. 252)

In Cason and Mui's sequential dictator game, framed as a market exchange, the dictator decides twice on an allocation of $\$ 40$ between herself and two distinct anonymous and randomly paired recipients. Before making the second allocation the dictator learns about an allocation chosen by another dictator from the subject pool in the relevant information treatment and about a birthday in the irrelevant information treatment. The data show mixed evidence for social influence. The differences in frequency of changes between the first and second decisions are statistically insignificant in the two treatments. However, Cason and Mui observe a statistically significant shift toward self-regarding choice in an irrelevant information treatment compared to no shift in a relevant information treatment, contrary to their expectations.

The mere fact of providing information about someone is a form of identification. Small and Loewenstein (2003) demonstrate that identifiability of a person increases caring. In their laboratory experiment, the subjects compensated others who lost money more when the loser had been identified than when they were not. In a field study, Small and Loewenstein compared altruism among people contributing to a charity. They find that people made bigger donations when their contributions would benefit a family that has been selected from a list than when they were told the family would be selected from a list. In the light of the literature on identifiability and dual- 
process models from social psychology, information about someone increases the likelihood of cognitive attention and thus deeper consideration.

The last line of research represents the exploration of reputation effects on indirect reciprocity by comparing the behavior towards strangers and towards people with an established reputation. Servátka (2006) uses a setup where the dictator is endowed with $\$ 10$. The dictator can send some or all of her endowment to an anonymous recipient. All the money sent is tripled by the experimenter. After all of the subjects make their allocations, they are rematched and participate in the next task. The design involves a role reversal in the second task: the recipients become dictators and vice versa. Before the new dictators make an allocation decision they receive information regarding the choice of their currently paired recipient in the first task. Servátka finds that the reputation of recipients triggered what would normally be interpreted as indirectly reciprocal behavior by dictators. As a result, the generosity of first dictators generated more generosity by the new ones.

After making this observation it is essential to ask: What caused the new dictators to give more than the first ones? The reputation not only informs about the type of a player but also carries two additional features. It provides information about the paired subject, therefore identifying him. Second, since the subjects are members of a bigger population, reputation can be seen as a signal of beliefs that the population holds regarding socially appropriate behavior, especially when the reputation is represented by a past decision of the subject. In that sense, a design examining reputation effects that takes the behavior towards a natural reference group of strangers as a baseline, tests a compound hypothesis. The compound hypothesis includes the hypotheses that reputation does not convey socially relevant information and that information about one's actions does not identify that person per se. The central idea of this paper is to discriminate behaviorally between the reputation, social influence, and identification and to directly confront their importance in decisionmaking. The results show that outside information about another subject's choice affects one's own decision mostly via indirect reciprocity. 


\section{Experimental Design and Procedures}

The experimental sessions took place in the Economic Science Laboratory at the University of Arizona in 2006 with undergraduate students serving as subjects. In each session, the participants were randomly divided into group $\mathrm{X}$ and group Y. One subject was randomly selected to be a monitor. The monitor was in charge of distributing and collecting envelopes with decision forms. All subjects were then seated in cubicles, group $\mathrm{X}$ in the front of the room and group $\mathrm{Y}$ in the back. In the general instructions the subjects were told they would participate in a multiple task experiment without specifying the nature of each task up front. They were also informed about the random matching procedures for each task to create an environment where one-shot games are played in an ongoing social interaction. ${ }^{2}$ They were told that a single task would be selected randomly for payoffs at the end of the experiment to control for wealth and portfolio effects. Once the experiment started, a new set of individual instructions were provided for each subject upon completion of each task.

The experimental design includes four conditions implemented acrosssubjects. ${ }^{3}$ Their outline along with the mechanisms transmitting information is presented in Table 1. Each condition consists of two tasks and involves a role reversal: the subjects who were dictators in one task act as recipients in the second one and vice versa while always paired with a different participant. Therefore, every subject has made only one decision during the session he or she participated in. In each task the following game was played between the dictator and the recipient: In the beginning the dictator was endowed with $\$ 10$ and could choose to send any whole dollar amount between 0 and 10 to the paired recipient. ${ }^{4}$ Any amount sent was tripled by the experimenter. The recipient had no decision to make, thus the final allocation was entirely decided by the dictator. The use of the dictator game was crucial because the dictator did not have to be concerned with any within-game strategic interdependence of her monetary payoffs on the other subject's decision. The design also included use of a double blind payoff protocol in which a subject's decisions are never linked with the subject's identity, thus minimizing

\footnotetext{
${ }^{2}$ Multiplicity of tasks invoking a strong social context has been explored by Cox (2000).

${ }^{3}$ I apply the idea of Cox's (2004) triadic design discriminating between actions motivated by preferences over the distribution of material outcomes and actions motivated by assignments of the intentions of others.

${ }^{4}$ For two surveys on the dictator game, see Camerer and Thaler (1995) and Roth (1995).
} 
possible experimenter demand effects on fairness behavior. ${ }^{5}$

Table 1. Experimental Conditions

\begin{tabular}{|l|c|c|}
\hline Conditions & Provided Info & Effects Caused by the Provided Info \\
\hline Reputation & recipient's dictator choice & reputation, social influence, identification \\
\hline Social Influence & different dictator's choice & social influence, identification \\
\hline Birthday & recipient's birthday & identification \\
\hline Base & no info & none \\
\hline
\end{tabular}

The four conditions differ in the informational structure and implementation. In the baseline condition (Base in tables), the dictator had no information about the paired recipient nor about any other subject participating in the experiment. In the reputation condition, $\mathrm{R}$, the dictator was informed about the currently paired recipient's decision as a dictator in the baseline condition as follows:

You are matched with a different person than in the previous task. The Group X person you are paired with for this task has previously made the following decision:

He/she changed his/her own account balance by ..., therefore, changing the account balance of the paired person by ....

Conditions baseline and $\mathrm{R}$ took place during the same session, baseline as the first task, called blue and $\mathrm{R}$ as the second, called yellow.

On the other hand, all subjects in the social influence condition, SI, participated in the first task as recipients, half in the blue task and half in the yellow task. In the second task of the session they were all dictators (i.e., if they were first assigned to the blue task, they were dictators in the yellow task and vice versa). The dictators were informed about a decision by a randomly chosen subject from the baseline condition in the following way:

Below, you are provided with a decision of a randomly chosen person from group X. This Group X person has previously made the following decision:

He/she changed his/her own account balance by ..., therefore, changing the account balance of the paired person by ....

\footnotetext{
${ }^{5}$ For a discussion on double blind payoff protocol see Hoffman et al. (1996).
} 
You are matched with a different person than in the previous task and with a different person than the one you have received information about.

The subjects were not told that the decisions were made by subjects who participated in the previous session. The fourth condition, called the birthday condition, BD, provided an irrelevant information about the birthday of the currently paired recipient to the dictators:

You are matched with a different person than in the previous task. The Group X person you are paired with for this task has a birthday on the ... day of one of the 12 months.

The BD condition controlled for general effects on fairness behavior of personal information about the individual affected by the dictator's decision and for costs of mental processing of information.

\section{Separating Reputation, Social Influence, and Identification Effects in Subjects' Behavior}

\subsection{Confounded and Pure Reputation Effects}

Subjects' behavior from all four conditions is summarized in Table 2. The results from baseline and reputation conditions will be discussed together since they took place during the same session. Figure 1 shows the amounts sent by dictators in the baseline condition represented by the solid black bar for each subject pair. The subjects are portrayed as they were paired in condition $\mathrm{R}$. The patterned bar represents the amounts sent by dictators in condition $\mathrm{R}$ after having observed choices of their paired recipients, i.e., the adjacent solid black bar. There were a total of 68 subjects participating in the two conditions; 34 subjects in the baseline condition and 34 subjects in condition $\mathrm{R}$. The dictators in the baseline condition and condition $\mathrm{R}$ sent on average $\$ 1.70$ and $\$ 3.03$, respectively.

Seven subjects sent zero to strangers in the baseline. Thus the behavior of $20.5 \%$ subjects in the baseline condition was consistent with the predictions for the self-regarding preferences model. Two dictators who observed such behavior also sent zero to selfish recipients, three sent $\$ 2$, one sent $\$ 4$, and 
one sent $\$ 5$. Seven other subjects sent $\$ 1$ to strangers. The paired dictators responded to this information as follows: two sent zero, one sent $\$ 1$, three sent $\$ 3$, and one sent $\$ 4$. Thirteen subjects in the baseline sent $\$ 2$. The dictators in $\mathrm{R}$ sent to them the amounts of zero (one subject), $\$ 2$ (one subject), $\$ 2$ (two subjects), $\$ 3$ (five subjects), $\$ 5$ (three subjects), and $\$ 6$ (one subject). There were four subjects who sent $\$ 4$ to strangers. Their paired dictators in $\mathrm{R}$ sent them $\$ 2, \$ 3, \$ 4$, and $\$ 10$. Another two subjects sent $\$ 4$ in the baseline and the dictators who observed their choices in $\mathrm{R}$ sent them $\$ 1$ and $\$ 10$. The last subject in the baseline condition sent $\$ 5$ to a stranger and his paired dictator sent him $\$ 3$ in condition $\mathrm{R}$.

Table 2. Treatment Results

\begin{tabular}{|l|c|c|}
\hline Data Category & Mean Amount Sent & Median Amount Sent \\
\hline Base & $1.70_{[1.27]\{34\}}$ & 2 \\
\hline Condition R & $3.03_{[2.39]\{34\}}$ & 3 \\
\hline Condition SI & $2.71_{[3.12]\{34\}}$ & 1.5 \\
\hline Condition BD & $2.03_{[1.95]\{35\}}$ & 2 \\
\hline
\end{tabular}

Standard deviations in brackets.

Number of subjects in braces.

The reputation condition represents the compound hypothesis. If a dictator observes the recipient's reputation, her generous action towards the recipient can be motivated by reputation, social influence, identification effects, and/or altruism. Since altruism is a possible explanation of behavior in all four treatments and is not of a direct focus of this paper, it will be excluded from further exposition. Parametric and nonparametric statistical tests in the first row of Table 2 test the joint effect of reputation, social influence, and identification effects. All of them report a statistically significant difference between the two conditions $(p<0.01)$. Further analysis examines which of the three effects (or their combination) is responsible for this difference.

The correlation coefficient between amounts sent by dictators in condition $\mathrm{R}$ and the choices of their paired recipients that they observed prior to making a decision is equal to 0.36. (Table 5). The Spearman's rank correlation test rejects the null that choices in baseline and $\mathrm{R}$ are independent. Seven subjects in condition $\mathrm{R}$ observed a reputation of zero. Two of them $(28.6 \%)$ did not send any money to their paired players, while the other five 
sent positive amounts; on average $\$ 2.14$. Twenty-seven subjects in the same condition observed a reputation strictly greater than zero. The average positive reputation was $\$ 3.26$. Three out of the twenty-seven $(11.1 \%)$ subjects did not send anything. The other twenty-four subjects sent positive amounts, with an average being $\$ 3.67$.

Table 3 summarizes the tested hypotheses and explains how pairwise comparison of the experimental conditions separate joint (rows 1, 2, and 4) and individual effects (rows 3, 5, and 6) of reputation, social influence, and identification on subjects' behavior. For each row, the second column of the table lists the effects responsible for different behavior between two compared conditions. The significance for each hypothesis is based on the respective Mann-Whitney test, reported in Table 2.

Table 3. Tested Hypotheses.

\begin{tabular}{|l|l|c|}
\hline Hypothesis $^{a}$ & \multicolumn{1}{|c|}{ Effects Tested } & Significance? $^{*}$ \\
\hline $\mathrm{R}>$ Base & reputation, social influence, identification & Yes \\
\hline $\mathrm{R}>$ BD & reputation, social influence & Yes \\
\hline $\mathrm{R}>\mathrm{SI}$ & reputation & Yes \\
\hline $\mathrm{SI}>$ Base & social influence, identification & No \\
\hline $\mathrm{SI}>\mathrm{BD}$ & social influence & No \\
\hline $\mathrm{BD}>$ Base & identification & No \\
\hline
\end{tabular}

${ }^{a}$ amounts sent in the respective conditions.

* Significance based on Mann-Whitney test, reported in Table 4.

To separate out the pure reputation effect, a comparison between dictators' behavior in conditions $\mathrm{R}$ and SI has to be made. A dictator's action in condition SI can be motivated by social influence, and/or identification. Thus, if a dictator behaves more generously in condition $\mathrm{R}$, the change in behavior can be attributed to a reputation effect causing indirect reciprocity. However, it is important to note that neither the reputation effect nor the other considered effects are known to be additive and so the observed behavior could be caused by their interaction.

Thirty four subjects who participated in condition SI were given information about the decisions made by dictators in the baseline. In that sense, the population of subjects in SI have seen the same information (but not about the person they were dealing with) as the population of subjects in $\mathrm{R}$ did. The SI subjects responded to the information as follows. From among those who observed $\$ 0$ two subjects also sent $\$ 0$, one sent $\$ 1$, one sent $\$ 4$, 
and three sent their whole endowments of $\$ 10$. There were seven subjects who learned that somebody else gave $\$ 1$. As a response, one subject sent $\$ 0$ and one sent $\$ 2$, and the remaining five subjects sent the same amount of $\$ 1$ to their paired recipients. From among the thirteen subjects who have seen a social influence information of $\$ 2$, three sent zero, three gave $\$ 1$, three $\$ 2$, one $\$ 3$, one $\$ 4$, one $\$ 5$, and one subject gave the whole $\$ 10$. Four SI subjects learned about another dictator's allocation of $\$ 3$ to the stranger. These dictators also gave $\$ 3$ (one subject), $\$ 4$ (one subject), and $\$ 5$ (two subjects). Both dictators who received information that someone else gave $\$ 4$ sent zero to their recipients. The person who knew that another dictator gave $\$ 5$, gave only $\$ 2$ to the paired recipient. Figure 2 shows the amounts sent by dictators in condition SI (patterned bar) and the information each subject observed (solid black line). The dictators after learning an allocation made by somebody else, sent on average $\$ 2.71$. Figure 3 compares the number of dictators in conditions $\mathrm{R}$ and $\mathrm{SI}$ that sent amounts varying from $\$ 0$ to $\$ 10$. The condition $\mathrm{R}$ data are portrayed by the patterned bar and data from condition SI by a solid black bar. Is there a clear evidence for pure reputation effects? Row 3 of Table 4 reports that the mean amount sent in conditions $\mathrm{R}$ and $\mathrm{SI}$ are not statistically significantly different. This is mainly due to the fact that there were four subjects in condition SI who gave $\$ 10$, compared to only two in condition R. However, the Mann-Whitney, median and Fisher's exact tests presented in the same row report that the presence of reputation effect in condition $\mathrm{R}$ made a weakly significant difference on dictators' behavior.

Table 4. Tests for Reputation, Social Influence, and Identification Effects

\begin{tabular}{|c|c|c|c|}
\hline $\operatorname{Data}^{a}$ & Means Test ${ }^{*}$ & Mann-Whitney Test ${ }^{*}$ & Median Test ${ }^{*}$ \\
\hline $\mathrm{R}$ vs. Base & $2.85(.003)$ & $2.70_{(.003)}$ & $10.38_{(.001)(.001)} \dagger$ \\
\hline $\mathrm{R}$ vs. $\mathrm{BD}$ & $1.90_{(.031)}$ & $1.82_{(.034)}$ & $3.25_{(.071)}(.059) \dagger$ \\
\hline $\mathrm{R}$ vs. $\mathrm{SI}$ & $.48_{(.317)}$ & $1.38_{(.084)}$ & $3.78_{(.052)(.044)} \dagger$ \\
\hline SI vs. Base & $1.73_{(.045)}$ & $.47_{(.319)}$ & $1.83_{(.177)(.140) \dagger} \dagger$ \\
\hline SI vs. BD & $1.08_{(.143)}$ & $.46_{(.323)}$ & $.03_{(.873)(.536)} \dagger$ \\
\hline BD vs. Base & $.82_{(.208)}$ & $0.38_{(.351)}$ & $2.30_{(.130)(.105)} \dagger$ \\
\hline
\end{tabular}


The correlation between amounts sent by dictators in condition SI and the social influence information that they observed prior to making a decision is equal to -0.20 (Table 5). The Spearman's rank correlation test does not reject the null that choices in the baseline and SI are independent. The information about social influence came from the same sample as the reputation in condition R. For that reason also seven subjects in condition SI observed a social influence of zero. Two of them $(28.6 \%)$ did not send any money to their recipients. The other five $(71.4 \%)$ sent positive amounts that were on average equal to $\$ 5.00 .{ }^{6}$ Also twenty-seven subjects in condition observed a reputation strictly greater than zero. The average positive social influence was $\$ 3.26$. Three out of the twenty-seven subjects did not send anything. The other twenty-four subjects sent positive amounts, with an average of $\$ 2.11$. The correlation between the positive social influence information and the amounts sent by dictators who observed this positive social influence information was equal to 0.13. However, the Spearman's rank correlation test again does not reject the null that these two samples are independent.

Table 5. Tests for Pairwise Correlation

\begin{tabular}{|l|c|c|c|}
\hline Data $^{a}$ & Correlation & Spearman's Test & Independence rejected? \\
\hline R vs. Base & 0.35 & 0.31 & Yes \\
\hline SI vs. Base & -0.20 & -0.01 & No \\
\hline${ }^{b} \mathrm{SI}_{+}$vs. Base & 0.13 & 0.24 & No \\
\hline
\end{tabular}

${ }^{a}$ amounts sent in the respective conditions.

${ }^{b} \mathrm{SI}_{+}=$positive social influence information.

Base $_{+}=$amounts sent by dictators who observed positive social influence information.

The tobit analysis of pooled dictators' choices based on the condition they participated in has the form: ${ }^{7}$

\footnotetext{
${ }^{6}$ At one of the conferences where this paper was presented a question was raised why did these dictators send such high amounts. Unfortunately, the current experiment was not designed to answer this specific question, hence I do not offer an explanation here. Further research aimed at the psychological forces behind the decisions is needed.

${ }^{7}$ Tobit is used here as an estimation technique dealing with restrictions on choices imposed by the experimental design, rather than a classical tobit model with a censored data, as for example, household income reported at some limit value. The controlled laboratory setting does not allow for possibilities such as that a subject gave $\$ 15$ but the experimenters only observed $\$ 10$. A proof that the likelihood technique yields consistent and asymptotically normal distributed estimates can be found in Schnedler (2005).
} 


$$
\text { Choice }_{t}=\alpha+\beta_{R} T_{R t}+\beta_{S I} T_{S I t}+\beta_{B D} T_{B D t}+\epsilon_{t}
$$

where $T_{R}, T_{S I}$, and $T_{B D}$ represent dummies for respective conditions. The bounds for the tobit estimation were imposed by the experimental design:

$$
\text { Choice }_{t} \in[0,10]
$$

The estimated coefficients are presented in the first row of Table 6 . The estimated $\beta_{R}$ is positive $(1.55)$ and significant $(p=0.037)$. Note that the marginal effect of $T_{R}$ is reported in a line below $\beta_{R}$. The marginal effect of participating in the reputation condition is equal to 1.16. Table 6 in the seventh row also reports tobit estimates of the parameters for the pooled data of the following relation between amounts sent by dictators to recipients, Choice $_{t}$, treatment dummies, and the received information in condition R, Information $_{R t}$, and in condition SI, Information SIt $_{\text {: }}$

$$
\begin{aligned}
& \text { Choice }_{t}=\alpha+\left(\beta_{R_{0}}+\beta_{R} \cdot \text { Information }_{R t}\right) \cdot T_{R t}+ \\
& +\left(\beta_{S I_{0}}+\beta_{S I} \cdot \text { Information }_{S I t}\right) \cdot T_{S I t}+\beta_{B D} T_{B D t}+\epsilon_{t}
\end{aligned}
$$

Table 6. Tobit Analysis of the Dictators' Responses to Reputation, Social Influence, and Birthday Information

\begin{tabular}{|l|c|c|c|c|c|c|c|}
\hline Data & $\hat{\alpha}$ & $\hat{\beta}_{R_{0}}$ & $\hat{\beta}_{R}$ & $\hat{\beta}_{S I_{0}}$ & $\hat{\beta}_{S I}$ & $\hat{\beta}_{B D}$ & LR test \\
\hline Dummies & $1.31_{(.014)}$ & - & $1.55_{(.037)}$ & - & $1.12_{(.132)}$ & $.06_{(.932)}$ & $6.51_{(.099)}$ \\
\hline marginals & .98 & - & 1.16 & - & .84 & .05 & - \\
\hline $\mathrm{R}$ & $1.33_{(.109)}$ & - & $.89_{(.025)}$ & - & - & - & $5.37_{(.020)}$ \\
\hline marginals & 1.14 & - & .77 & - & - & - & - \\
\hline SI & $3.68_{(.009)}$ & - & - & - & $-.83_{(.203)}$ & - & $1.69_{(.193)}$ \\
\hline marginals & 2.57 & - & - & - & -.58 & - & - \\
\hline Pooled & $1.32_{(.010)}$ & $-.04_{(0.968)}$ & $.92_{(.025)}$ & $2.29_{(.024)}$ & $-.69_{(.098)}$ & $.077_{(.918)}$ & $14.33_{(.014)}$ \\
\hline marginals & 1.00 & -.03 & .69 & 1.73 & -.52 & .06 & - \\
\hline
\end{tabular}

Marginal effects are reported in a row below the estimated coefficients. p-values in parentheses.

The estimated $\beta_{R}$ for the pooled data from the above relation is also positive $(0.92)$ and significant $(p=0.025)$. The marginal effect estimating 
the influence of reputation information on amounts sent by dictators is equal to 0.69. The third and fourth row of Table 6 reports the Tobit estimates and the marginal of reputation effect for 34 subjects participating in condition R. The individual treatment data yield a similar result. Hence, the tobit estimation supports the conclusion that the reputation triggered indirect reciprocity.

The relevance of indirect reciprocity is supported by other studies as well. Nowak and Sigmund (1998) examined an evolutionary process based on simulations of a repeated helping game where a donor can help the recipient at a cost smaller than the benefit. Based on previous behavior, the recipient is awarded with an image score to which the donors respond. They find that the discriminating types are evolutionary stable. Also Seinen and Schram (2001) experimentally study the helping game and observe that indirect reciprocity is important since many donors base their actions on the image score of the recipient and on their own score as well. Engelmann and Fischbacher (2002) introduce two types of players - with and without the image score and separate pure indirect reciprocity from incentives for strategic reputation building on the helping rate. They find that pure indirect reciprocity is relevant but also that the helping choice seems to be influenced by strategic considerations. In their setting the strategic players do better than nonstrategic ones and non-reciprocal players do better than reciprocal players. Several other papers examine indirect reciprocity in different experimental settings. For example, Fehr and Gächter's (2002) study demonstrates its presence in altruistic punishment in a public good game. Dufwenberg et al. (2001) compare the effects of direct versus indirect reciprocity in the investment game and find that receivers are more rewarding in the indirect reciprocity treatment.

\subsection{Social Influence Effect}

Does the statistical analysis support the existence of social influence effects in the data? To make that claim, one needs to compare the results from conditions SI and BD. In condition SI, subject's behavior could be motivated by social influence and/or identification effects. ${ }^{8}$ On the other hand,

\footnotetext{
${ }^{8}$ Note that this is a weak form of identification as only a behavior of different person from the other group is identified. An alternative design would include information about a different dictator's previous choice and birthday information of the paired person. The downside of such procedure is the increased number of various information revealed to
} 
in condition BD only the identification effect is present. Thus, the difference in subjects' behavior between these two treatments could be attributed to social influence.

Thirty six subjects participated in condition BD. One subject marked two answers and was excluded from the data analysis. However, this person still served as a recipient in the other task, therefore allowing for an observation made by the paired player. Since the birthday is irrelevant information, I only present the distribution of choices in this condition. Twelve subjects out of thirty five sent zero, three subjects sent $\$ 1$, seven sent $\$ 2$, five $\$ 3$, three $\$ 4$, four $\$ 5$, and one subject sent $\$ 7$. On average the subjects in condition $\mathrm{BD}$ sent $\$ 2.03$. The behavior of dictators in conditions $\mathrm{SI}$ and $\mathrm{BD}$ is graphically compared in Figure 4. It shows the number of subjects in conditions SI and BD that sent amounts between $\$ 0$ and $\$ 10$. The social influence raised the average amount sent by dictators by $\$ 0.68$ more than in BD. The statistical analysis of data provides mixed evidence of social influence effects. The means test reported in Table 4 in row 5 does not detect a statistically significant difference and neither do the nonparametric tests. On the other hand, tobit estimate for social influence effect of information is negative and statistically significant for the pooled data but insignificant for the dummy equation and individual SI-condition data as presented in Table 6 in rows seven, one, and five, respectively. The marginal effects of social influence are again reported in a line below the estimated coefficients.

\subsection{Identification Effect}

The identification effect can be separated from the data by comparing the behavior of subjects in condition BD with the baseline. In BD the dictator's actions can be motivated by identification, whereas in the baseline there is no such effect since the dictators do not receive any type of information. Figure 5 shows the number of dictators in condition BD and in the baseline that sent amounts between $\$ 0$ and $\$ 10$. Providing irrelevant information about the recipients' birthday increased on average the amounts sent by dictators by $\$ 0.33$. This result goes against Cason and Mui's finding that an irrelevant information causes subjects to behave in a more self-regarding way. All tests presented in the last row of Table 4 reveal that the difference in behavior between conditions $\mathrm{BD}$ and the baseline is statistically insignificant, unlike

dictators in comparison to other conditions. 
in Small and Loewenstein's study. The conclusion that identification effect increased the generosity of dictators is not supported by the estimates of the above tobit models either. The estimated coefficients on participation in condition BD reported in rows one and seven of Table 6 are small and highly insignificant.

\section{Conclusions}

This paper reports an experiment that separates the effects of reputation, social influence, and identification across four dictator games. The experimental conditions differ in the information provided to the decisionmakers. The data support the previous findings that reputation information triggers indirect reciprocity. The statistical analysis also reveals that the reputation has stronger effects on dictators than does social influence and identification. Based on the experimental results one can conjecture that an active participation in social norm creation and their enforcement governs people's behavior in the presented environment to a higher degree than does conformism. Taken together, this study increases our understanding of the ways in which information about others' actions affects people's own actions, and thus helps to identify the mechanisms of social transmission of impulses towards certain types of behavior.

\section{References}

[1] Berg, J., J. Dickhaut, and K. McCabe, "Trust, Reciprocity, and Social History." Games and Economic Behavior, July 1995, 10(1), 122-42.

[2] Camerer, C. and R. H. Thaler, "Anomalies: Ultimatums, Dictators and Manners, Journal of Economic Perspectives, vol. 9 (2), 1995, 209219.

[3] Cason, T. N. and V.-L. Mui, "Social Influence in the Sequential Dictator Game," Journal of Mathematical Psychology, 42, 1998, 248-65.

[4] Cox, J. C., "How to Identify Trust and Reciprocity," Games and Economic Behavior, 46, 2004, 260-281.

[5] Cox, J. C., "Trust and Reciprocity: Implications of Game Triads and Social Contexts," University of Arizona discussion paper, September 
1999, revised 2000.

[6] Dufwenberg, M., U. Gneezy, W. Güth, and E. van Damme, "Direct vs. Indirect Reciprocity: An Experiment," Homo Oeconomicus, 2001, 19-30.

[7] Engelmann, D. and U. Fischbacher, "Indirect Reciprocity and Strategic Reputation Building in an Experimental Helping Game," working paper No. 132, Institute for Empirical Research in Economics, University of Zurich, November 2002.

[8] Fehr, E. and S. Gächter, "Altruistic Punishment in Humans," Nature, NATURE 415, 10 January 2002, 137-140.

[9] Hoffman, E., K. McCabe, and V. L. Smith, "Social Distance and OtherRegarding Behavior in Dictator Games." American Economic Review, 3, 1996, 653-660.

[10] Knez, M. J. and C. F. Camerer, "Social Comparison and Outside Options in 3-person Ultimatum Games," Games and Economic Behavior, 10, 1995, 165-194.

[11] Nowak, M.A. and K. Sigmund, "Evolution of Indirect Reciprocity by Image Scoring," Nature, 393, 1998a, 573-7.

[12] Roth, A. "Bargaining Experiments," In the Handbook of Experimental Economics, J. Kagel and A. Roth eds., 253-348, Princeton University Press, Princeton: New Jersey.

[13] Schnedler, W., "Likelihood Estimation for Censored Random Vestors," Econometric Reviews, 24(2), 2005, 195-217.

[14] Seinen, I. and A. Schram, "Social Status and Group Norms: Indirect Reciprocity in a Helping Experiment," CREED, University of Amsterdam working paper, 2001.

[15] Servátka, M., "Does Generosity Generate Generosity?," University of Arizona discussion paper, November 2006.

[16] Small, D. A. and G. Loewenstein, "Helping a Victim or Helping the Victim: Altruism and Identifiability," Journal of Risk and Uncertainty, $26: 1,2003,5-16$. 


\section{Appendix}

\section{$5.1 \quad$ Instructions}

\subsubsection{General Instructions - All Conditions}

No Talking Allowed

Now that the experiment has begun, we ask that you do not talk or communicate any longer with each other. Because we will not be available to assist you, it will not be possible for you to ask questions. In case there is still something that you do not understand, you are kindly requested to read the instructions again.

Monitors and Two Groups

A monitor has been selected randomly from among those of you who came here today. The rest of you have been divided randomly into two groups, called Group X and Group Y. Group X people are seated in the front row A. Group Y people are asked to sit at the back of the room (row D).

Multiple Tasks

You will be asked to participate in multiple tasks during the experiment. The instructions for each task will be given to you after finishing the previous one. The end of the experiment will be announced to you after completing certain number of tasks.

Anonymity

Each person in Group $\mathrm{X}$ will be randomly matched with a person in Group Y. No one will learn the identity of the person she/he is matched with. In each task a person in Group $\mathrm{X}$ will be matched to a different person in Group Y. There is no chance of being matched with the same person more than once during the entire experiment.

Initial Account Balances

Each person in each group will be credited with 10 experimental dollars at the beginning of each experimental task.

Money Payoffs

The information about final account balances in each task will be recorded by the experimenters. At the end of the experiment a die will be rolled in front of you to decide the task for which you will be paid in cash. The 
remaining balance in your dollar account from the randomly selected task will be paid to you in cash at the rate of 1 U.S. dollar per 1 experimental dollar.

Complete Privacy

This experiment is structured so that no one, neither the experimenters nor the other subjects nor anyone else will ever know the personal decision of anyone in the experiment. This is accomplished by the following procedure. You will collect your money payoff contained in a sealed envelope, from a mailbox that only you can open (with your key). Your privacy is guaranteed because neither your name nor your student ID number will appear on any form that records your decisions in this experiment. The only identifying mark in all records will be your seat number and the number engraved on your key which is known only by you. However, although the experimenters will not know your identity, they have a way to map your decisions into your own payoff correctly. At the end of the experiment, you will walk one by one to the waiting room where the mailboxes are to collect your money payoff envelope. The key and mailbox are labeled with the same number. But you will be the only person in possession of that key and the only one who knows your key number. When collecting the envelope from your mailbox, you are kindly requested not to open it immediately. You should wait until you leave the building. After collecting the envelope, you must return your key by throwing it in a key-return box next to the waiting room door.

Your Private Label

At the end of the experiment you will be given a key in a sealed envelope. There will be a 5-digit number engraved on your key. The entered number will be used to select the box that your key can open, which will contain a sealed envelope with your earnings inside.

The Role of the Monitor

A monitor was randomly chosen from among the students who volunteered for today's experiment. The monitor will be in charge of distributing and collecting the envelopes with decision form sheets inside little boxes that contain the envelopes containing mailbox keys. The monitor will also be asked to watch and make sure that the experimenters actually follow the procedures that have been explained here.

Decision Forms 
Prior to each task you will be given a decision form on a colored paper. After completing the task, please put the decision form in the enclosed envelope, seal it and give it to the monitor. If you did not get a decision form, you are not making a decision in that task. In such case, please return the empty envelope.

Please, read the instructions for each task very carefully.

\subsubsection{Blue Task Instructions - Baseline Condition}

\section{Initial Account Balances}

Each person in Group Y is credited with 0 (zero) experimental dollars. Each person in Group X is credited with 10 (ten) experimental dollars. As explained below, each Group X person will have a decision to make about what to do with her/his Blue Task endowment.

Decisions

Each Group X person has a single decision to make. He/she can decide to change or not the dollar account balances of both people. The Group Y person has no decision to make. Hence, after the Group X person makes his/her decision, the task ends and the account balance of both persons for this task cannot be changed any more.

The Group X Decision Task

Every dollar given by a person in Group X to a person in Group Y will be tripled by the experimenters. If Person X decides to increase the Y Person's account balance by $\$ 3$ then the X person's account balance decreases by $\$ 1$. The Group X person cannot increase the other person's account balance by more than $\$ 30$. The following table shows how this works.

Group Y Has No Decision to Make

The Group Y people do not have any decision to make in Blue Task. This means that they will keep all of the tripled amount sent to them by individuals in Group X.

Examples 


\begin{tabular}{|c|c|c|}
\hline $\begin{array}{c}\text { If the Group X } \\
\text { Person Gives }\end{array}$ & $\begin{array}{c}\text { The Experimenters } \\
\text { Triple the Amount }\end{array}$ & $\begin{array}{c}\text { And the Group Y } \\
\text { Total Payoff is }\end{array}$ \\
\hline 0 & $3 * 0$ & 0 \\
\hline 1 & $3 * 1$ & 3 \\
\hline 2 & $3 * 2$ & 6 \\
\hline 3 & $3 * 3$ & 9 \\
\hline 4 & $3 * 4$ & 12 \\
\hline 5 & $3 * 5$ & 15 \\
\hline 6 & $3 * 6$ & 18 \\
\hline 7 & $3 * 7$ & 21 \\
\hline 8 & $3 * 8$ & 24 \\
\hline 9 & $3 * 9$ & 27 \\
\hline 10 & $3 * 10$ & 30 \\
\hline
\end{tabular}

- If Person $\mathrm{X}$ decides to change his/her account balance by -6, person Y's account changes by +18 . The payoffs for this task will yield 4 dollars for Person X and 18 dollars for Person Y.

- If Person $\mathrm{X}$ decides to change his/her account balance by 0 , person Y's account does not change. The payoffs for this task will yield 10 dollars for Person X and 0 dollars for Person Y.

\subsubsection{Blue Task Decision Form for a Person from Group X - Base- line Condition}

My initial account balance is $\$ 10$. The paired person from group $\mathrm{Y}$ initial account balance is $\$ 0$. Each dollar I give to the paired person is multiplied by 3 by the experimenter.

My decision is to give the following amount to the paired person. (Please circle one.)

$\begin{array}{lllllllllll}\$ 0 & \$ 1 & \$ 2 & \$ 3 & \$ 4 & \$ 5 & \$ 6 & \$ 7 & \$ 8 & \$ 9 & \$ 10\end{array}$

\subsubsection{Yellow Task Instructions - Conditions R, SI, and BD}

Initial Account Balances 


\begin{tabular}{|c|c|c|}
\hline $\begin{array}{c}\text { If the Group Y } \\
\text { Person Gives }\end{array}$ & $\begin{array}{c}\text { The Experimenters } \\
\text { Triple the Amount }\end{array}$ & $\begin{array}{c}\text { And the Group X } \\
\text { Total Payoff is }\end{array}$ \\
\hline 0 & $3 * 0$ & 0 \\
\hline 1 & $3 * 1$ & 3 \\
\hline 2 & $3 * 2$ & 6 \\
\hline 3 & $3 * 3$ & 9 \\
\hline 4 & $3 * 4$ & 12 \\
\hline 5 & $3 * 5$ & 15 \\
\hline 6 & $3 * 6$ & 18 \\
\hline 7 & $3 * 7$ & 21 \\
\hline 8 & $3 * 8$ & 24 \\
\hline 9 & $3 * 9$ & 27 \\
\hline 10 & $3 * 10$ & 30 \\
\hline
\end{tabular}

Each person in Group X is credited with 0 (zero) experimental dollars. Each person in Group Y is credited with 10 (ten) experimental dollars. As explained below, each Group Y person will have a decision to make about what to do with her/his Yellow Task endowment.

Decisions

Each Group Y person has a single decision to make. He/she can decide to change or not the dollar account balances of both people. The Group X person has no decision to make. Hence, after the Group Y person makes his/her decision, the task ends and the account balance of both persons for this task cannot be changed any more.

The Group Y Decision Task

Every dollar given by a person in Group $\mathrm{Y}$ to a person in Group X will be tripled by the experimenters. If Person $\mathrm{Y}$ decides to increase the $\mathrm{X}$ Person's account balance by $\$ 3$ then the Y person's account balance decreases by $\$ 1$. The Group Y person cannot increase the other person's account balance by more than $\$ 30$. The following table shows how this works.

Group X Has No Decision to Make 
The Group X people do not have any decision to make in Yellow Task. This means that they will keep all of the tripled amount sent to them by individuals in Group Y.

Examples

- If Person Y decides to change his/her account balance by 0, person $\mathrm{X}$ 's account does not change. The payoffs for this task will yield 10 dollars for Person $\mathrm{Y}$ and 0 dollars for Person X.

- If Person Y decides to change his/her account balance by -6, person $\mathrm{X}$ 's account changes by +18 . The payoffs for this task will yield 4 dollars for Person Y and 18 dollars for Person X.

\subsubsection{Yellow Task Decision Form for a Person from Group Y - Condition R}

Information

You are matched with a different person than in the previous task. The Group X person you are paired with for this task has previously made the following decision:

$\mathrm{He}$ /she changed his/her own account balance by ......... therefore, changing the account balance of the paired person by .........

Decision

My initial account balance is $\$ 10$. The paired person from group $\mathrm{X}$ initial account balance is $\$ 0$. Each dollar I give to the paired person is multiplied by 3 by the experimenter.

My decision is to give the following amount to the paired person. (Please circle one.)

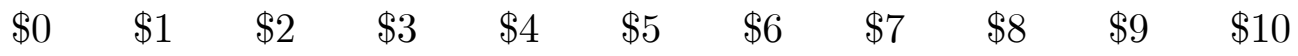

\subsubsection{Yellow Task Decision Form for a Person from Group Y - Condition SI}

Information

Below, you are provided with a decision of a randomly chosen person from group X. This Group Y person has previously made the following decision: 
He/she changed his/her own account balance by ......... , therefore, changing the account balance of the paired person by ..........

You are matched with a different person than in the previous task and a different person than the one you have received information about.

Decision

My initial account balance is $\$ 10$. The currently paired person from group $\mathrm{X}$ initial account balance is $\$ 0$. Each dollar I give to the paired person is multiplied by 3 by the experimenter.

My decision is to give the following amount to the paired person. (Please circle one.)

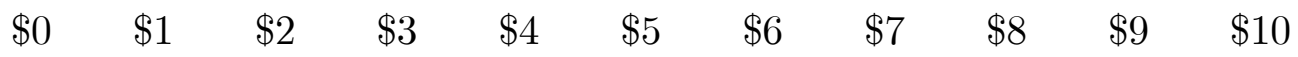

\subsubsection{Yellow Task Decision Form for a Person from Group Y - Condition BD}

Information

You are matched with a different person than in the previous task. The Group X person you are paired with for this task has a birthday on the ........... day of one of the 12 months.

Decision

My initial account balance is $\$ 10$. The paired person from group $\mathrm{X}$ initial account balance is $\$ 0$. Each dollar I give to the paired person is multiplied by 3 by the experimenter.

My decision is to give the following amount to the paired person. (Please circle one.)

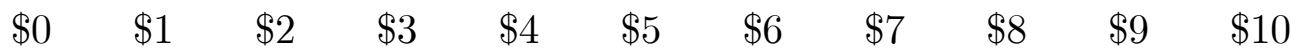

\subsection{Figures}




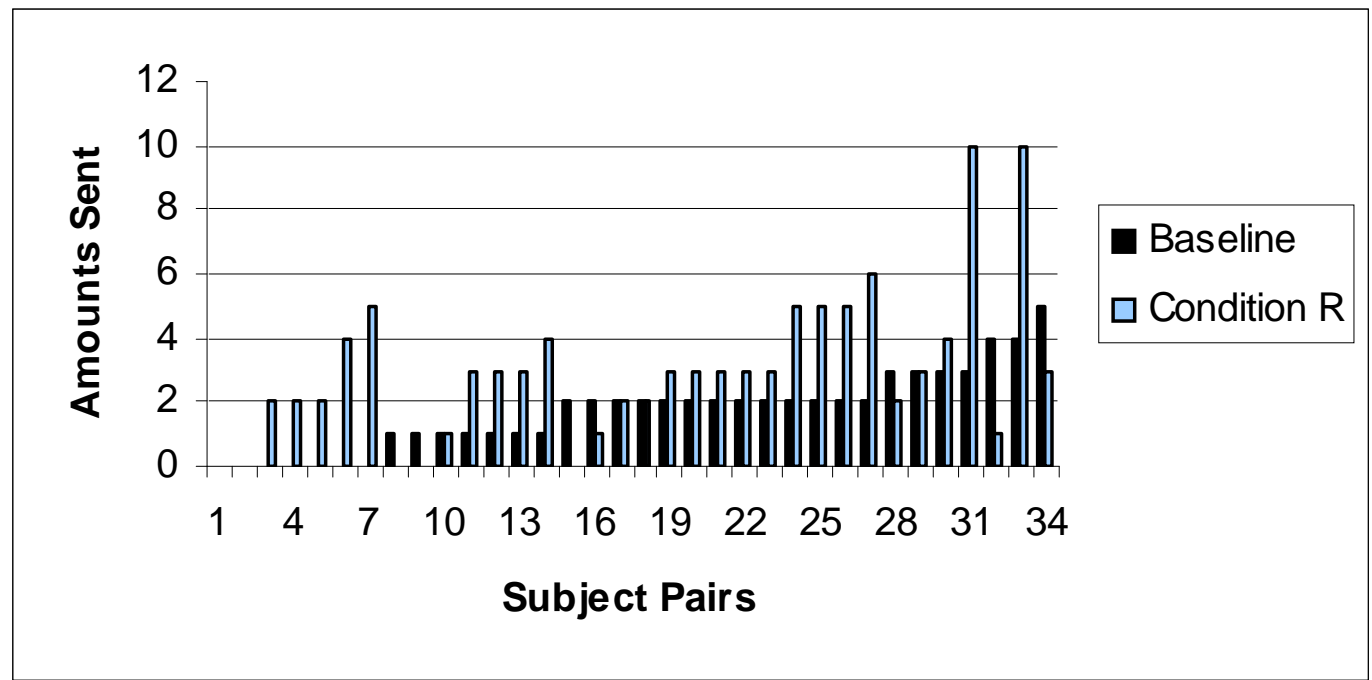

Figure 1. Subjects' Behavior in Baseline and Reputation Conditions.

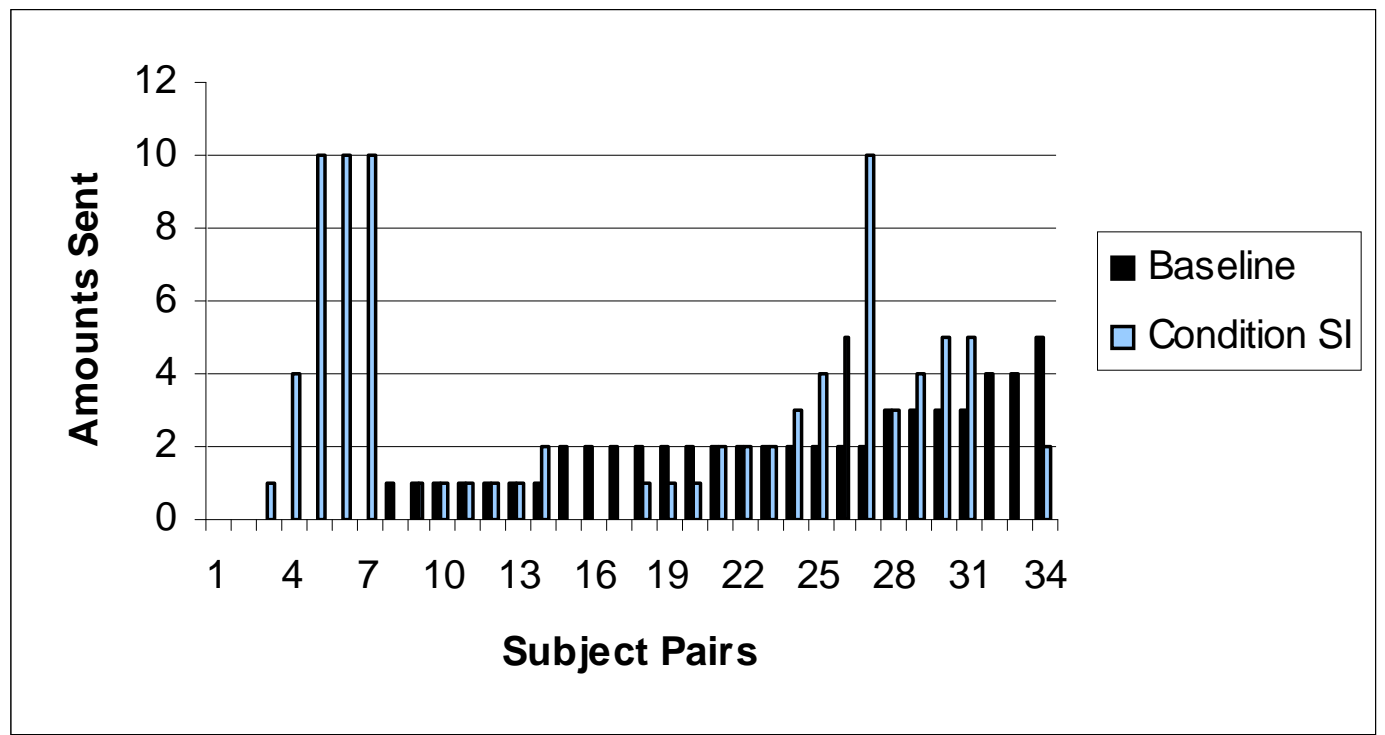

Figure 2. Subjects' Behavior in Stranger and Social Influence Conditions. 


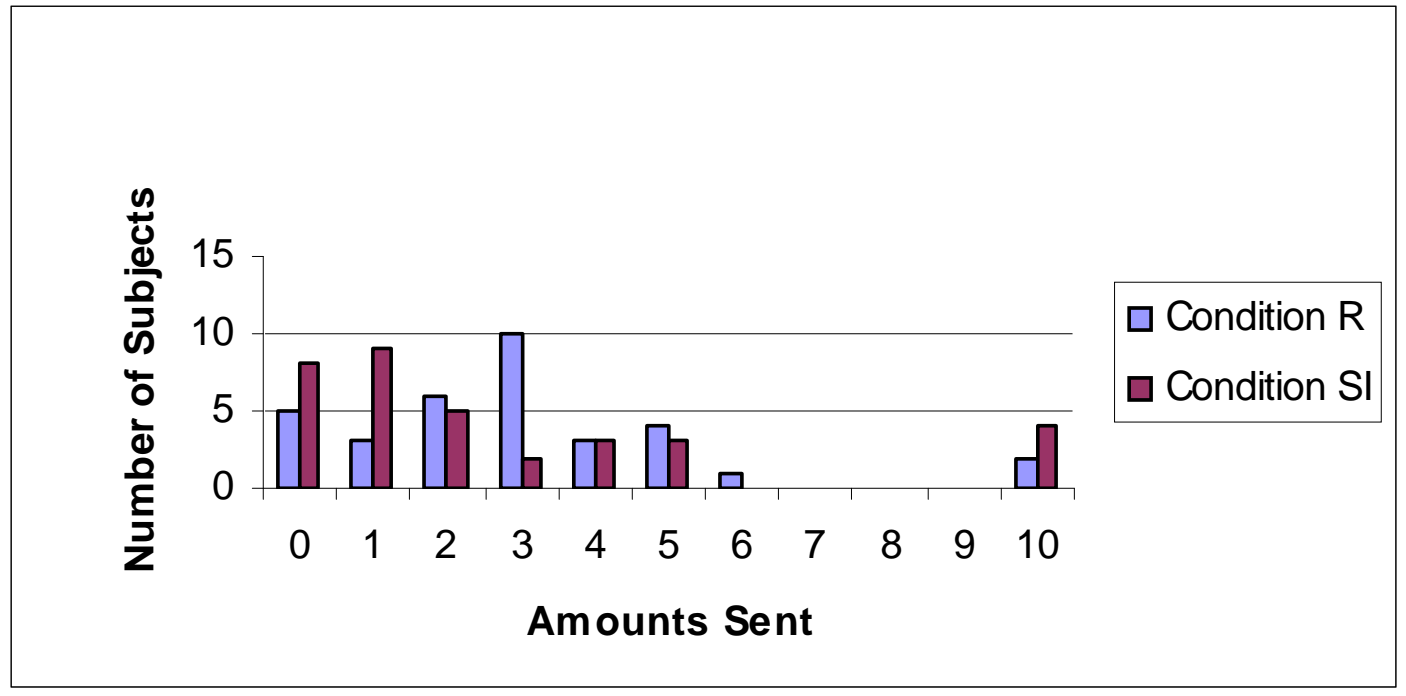

Figure 3. Subjects' Behavior in Reputation and Social Influence Conditions.

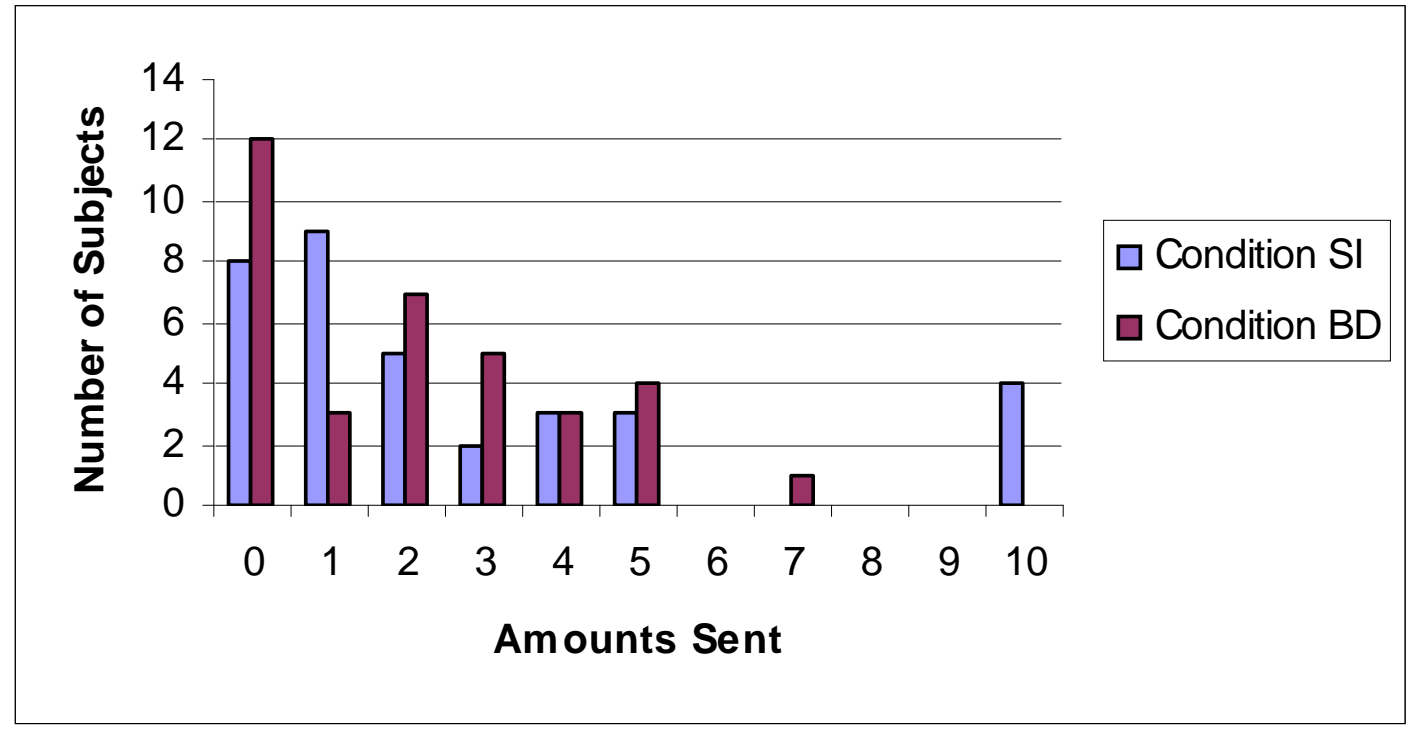

Figure 4. Subjects' Behavior in Social Influence and Birthday Conditions. 


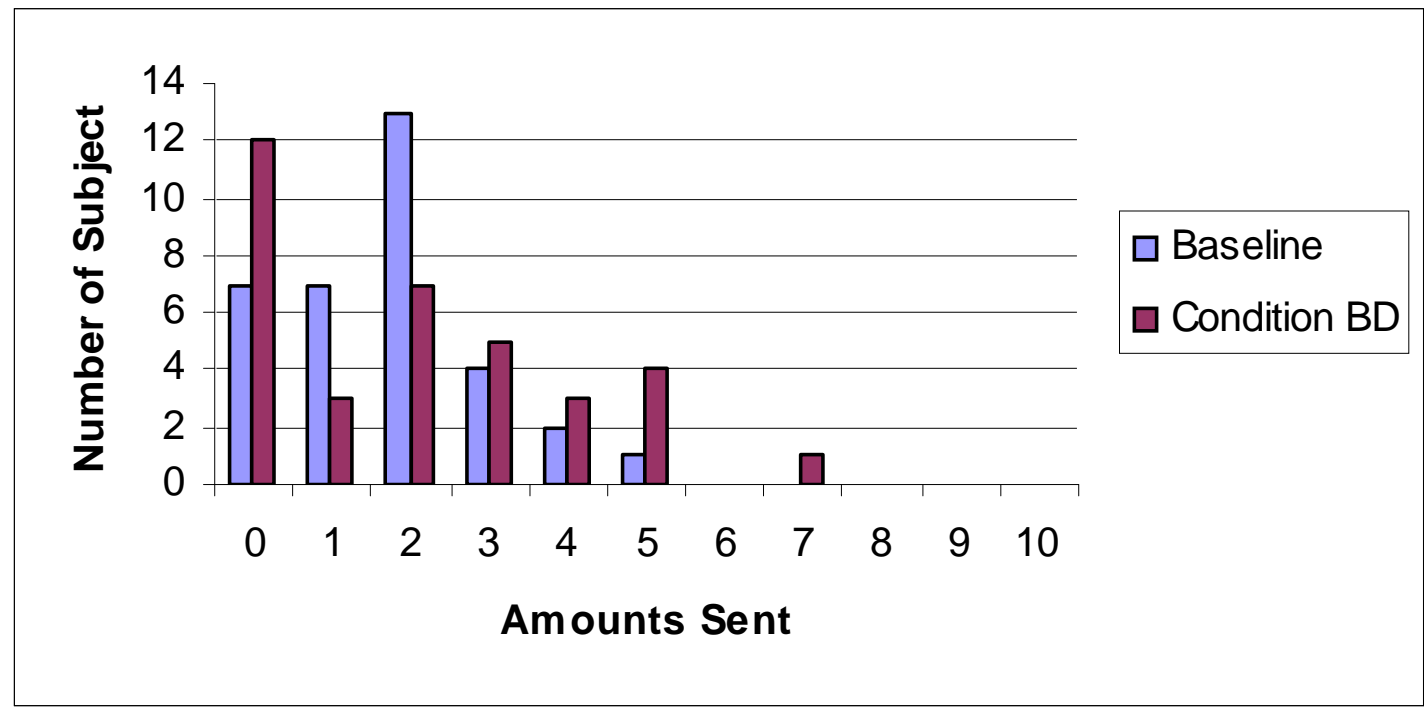

Figure 5. Subjects' Behavior in Stranger and Birthday Conditions. 